\title{
A CIÊNCIA DA INFORMAÇÃO NA SOCIEDADE MULTICULTURAL: O PARADIGMA SOCIAL COMO PARADIGMA EMERGENTE ${ }^{\mathrm{i}}$
}

\author{
Jorge Santa Anna \\ Mestrando do PPG Gestão e Organização do Conhecimento - UFMG \\ jorjao20@yahoo.com.br
}

\section{Resumo}

Os paradigmas que sustentam as áreas do conhecimento e as devidas profissões a elas relacionadas devem estar em constante redefinição, considerando os novos desafios e mudanças que ocorrem ao longo dos tempos. Esses paradigmas devem emergir em consonância com as necessidades do ambiente social, considerando, principalmente, limitações e especificidades do ser humano. Assim, este estudo teórico tematiza a Ciência da Informação e sua redefinição na Sociedade Multicultural. Objetiva discorrer acerca das contribuições do paradigma social, refletindo acerca de sua consolidação como paradigma emergente para a Ciência da Informação na Sociedade Multicultural. Discorre acerca dos aspectos da Sociedade Multicultural e as características do paradigma social da Ciência da Informação. Apresenta fundamentação que justifica tal paradigma como emergente para a sociedade pós-moderna e para a Ciência da Informação. Conclui que o acesso à informação, a democratização do conhecimento, bem como o estudo da comunicação entre humanos, tendências essas oriundas do paradigma social, constituem os pilares centrais na promoção de uma sociedade pautada em diferenças, mas conduzida pela libertação e aceitação.

Palavras-chave: Sociedade Multicultural. Paradigmas da Ciência da Informação. Paradigma social.

\section{INTRODUÇÃO}

A sociedade atual está permeada por distintos paradigmas, os quais são os elementos sustentadores das transformações e, ao mesmo tempo, são eles que asseguram o equilíbrio entre as forças que direcionam os caminhos a serem seguidos pelos distintos atores sociais, sejam as organizações, sistemas, instituições e profissões, garantindo, dessa forma, a convergência de esforços em prol de objetivos similares.

Não é novidade acerca da existência de paradigmas específicos que conduziram as diferentes sociedades ao longo dos tempos, fato esse que permitiu a separação das sociedades em diferentes estágios evolucionários, como colocado por Toffler (2003), delimitando-se como épocas bem definidas: a sociedade sustentada na agricultura, na indústria e, por fim, na informação.

A cada uma dessas sociedades, foi estabelecido um paradigma específico, aceito em um determinado período de tempo (paradigma dominante) e sendo refutado à medida que novas tendências não eram contempladas pelo paradigma dominante, o que exigia a reconfiguração de um ou vários paradigmas a serem instituídos. Em todos os casos, segundo Santos (2011), o paradigma é dominante enquanto estiver cumprindo com as "promessas" apresentadas no momento de sua elaboração. O não cumprimento viabiliza a formação de um paradigma mais abrangente, que, durante um certo período de transição, é visto como o paradigma emergente, preparando-se para sua concretização.

A sociedade atual está situada nesse período de transição, em que o paradigma teocrático, proposto na Idade Média, foi refutado e, como consequência, surgiram novos desafios a serem superados em períodos cada vez mais curtos. Santos (2011) defende que a Sociedade Moderna, embora tenha uma concepção paradigmática sustentada por ideias democráticas e científicas - no que se refere à igualdade de direitos proposta quando da formação dos estados modernos - tal concepção não foi devidamente cumprida, e muitos sistemas de 
controle da atualidade trabalham em prol de uma sociedade em que as diferenças tornamse cada vez mais visíveis. Portanto, é preciso pensar em um paradigma que emerge para a Sociedade Pós-moderna, em que deva prevalecer uma concepção pautada na liberdade e igualdade de direitos para todos.

Alguns conceitos podem ser aqui citados a fim de demonstrar a necessidade de um novo paradigma para esta sociedade, tais como: acesso à informação, democratização do conhecimento, liberdade de expressão, igualdade de direitos, socialização, trabalho coletivo, aprendizagem, colaboração, dentre tantos outros. Certamente, esses conceitos podem ser alcançados, principalmente, graças ao avanço das tecnologias, as quais permitiram a reconfiguração de um novo espaço social, em que fronteiras geográficas e temporais não são mais percebidas. Em decorrência dessa reconfiguração, assiste-se a sociedade do conhecimento, da informação, da colaboração, da aprendizagem, em redes, do compartilhamento, dentre tantas outras nomenclaturas descritas na literatura.

Assim, entende-se que o paradigma emergente deve contemplar todos esses conceitos supracitados, o que não é contemplado pelo paradigma até então dominante - pautado nos ideais democráticos e científicos - conforme descrito na tese de Santos (2011), que considera esta sociedade como a sociedade da informação e do conhecimento, a qual deveria condicionar uma concepção paradigmática sustentada pela igualdade de direitos. No entanto, a definição desse novo paradigma pode ser emblemática, principalmente devido à ambiguidade, subjetividade e amplitude atribuída ao termo informação e conhecimento, sobretudo pela falta de delimitação contemplada por cada um desses elementos, considerados como os objetos da sociedade pós-moderna.

Há complexidades no entendimento atribuído ao termo informação e conhecimento. "[...] Tanto o conhecimento quanto a informação estão incorporados na linguagem e ambos envolvem um dispositivo conceitual que não é derivado dos dados que recebemos do mundo dos fenômenos mas lhe é imposto [...]" (MCGARRY, 1999, p. 39). Como consequência dessa dispersão, segundo o mesmo autor, "[...] cada indivíduo organiza o mundo dum modo único que torna muito difícil organizar o conhecimento público em estruturas aceitáveis para todos [...]". Para esse mesmo autor, a informação representa um elemento subjetivo e disperso que, ao ser processada ou contextualizada, agregará diferentes valores aos sujeitos que dela se apropriam, condicionando a formação do conhecimento. Informação e conhecimento, portanto, assumirão diferentes percepções, dependendo do modo de como o indivíduo se apropria e utiliza esses elementos em seu contexto social.

Portanto, vive-se na atualidade, uma multiplicidade de costumes, de tendências, de gostos, enfim, a democratização do conhecimento, iniciada, em grande parte, no período das Grandes Navegações, conforme pontuado por Burke (2003), desencadeou essas mudanças na sociedade pós-moderna, a qual pode ser denominada, se considerarmos a importância do ser humano e sua liberdade, de Sociedade Multicultural. Com efeito, a Sociedade Multicultural pode constituir uma característica da Sociedade Pós-Moderna, ou seja, representa um dos produtos alcançados com a consolidação da Sociedade da Informação e do Conhecimento.

Essa sociedade caracteriza-se pela diversidade existente nas culturas que estão inseridas em seu meio, sendo as culturas aqui entendidas como um elemento mutante que extravasa as concepções tradicionais e adquirem novas formas de sociabilidade e de vivências, considerando-se a busca do ser humano por liberdade, fraternidade $\mathrm{e}$ igualdade (CANEN; CANEN, 2005).

Sendo assim, tendo em vista a consolidação de uma sociedade pautada na liberdade e igualdade de direitos (paradigma dominante), conforme esclarecido por Santos (2011), no contexto da sociedade da informação, é importante questionar como as áreas do conhecimento humano, bem como as profissões - consideradas como bases para a produção e aplicação do conhecimento na melhoria da qualidade de vida do ser humano - irão reformular seus paradigmas. Essa reformulação é necessária, pois é através das tendências sociais (caracterizadas como os costumes, os valores, hábitos e nova culturas que sustentam a Sociedade Pós-Moderna), que as profissões redefinem os processos de intervenção na resolução de problemas, como nos ensina Cunha (2006). 
Entende-se que as tendências sociais acometem todas as profissões e atores da sociedade (CUNHA, 2006), tendo especial interferência nas profissões, cujo objeto de estudo é a informação (caracterizada como o insumo básico para a produção de conhecimento e desenvolvimento pessoal e social), sendo que esse objeto (mesmo por sua natureza subjetiva ao ser apropriado pelo ser humano) é compartilhado por inúmeras áreas, consolidando um rigoroso processo interdisciplinar, como acontece com a Ciência da Informação (LE COADIC, 2004).

As dificuldades aumentam nessa área do conhecimento, sobremaneira, por ela ainda não possuir uma constituição identitária (SIQUEIRA, 2010), como também devido à amplitude do termo informação, que não permite uma única abordagem para a área, dificultando sua delimitação como uma área científica, mas sua contribuição tem sido profunda para as ciências documentais, como nos ensina Silva e Ribeiro (2002).

Considerando as tendências da Sociedade Multicultural, entende-se que, ao contrário das sociedades anteriores, cujo objeto tem tido uma concepção mais concreta, na atual sociedade, o fator humano passa a ser o foco das atenções, haja vista dar conta de atender as necessidades múltiplas do mundo pósmoderno, conforme em Santos (2011). No caso da Ciência da Informação, a ambiguidade da informação, bem como seu tratamento por meio de tecnologias, causa o mesmo problema das sociedades anteriores, uma vez que o foco adentra-se a algo concreto, que requer o uso de técnicas e métodos específicos.

Esse problema pode ser resolvido se questões humanistas vieram à tona $\mathrm{e}$ consolidarem um paradigma pautado no uso e no usuário da informação, além de considerar as questões multiculturais, o que caracteriza esse campo do saber como uma ciência social (LE COADIC, 2004; ARAÚJO, 2014; CAPURRO, 2003).

Portanto, para Capurro (2003), um dos paradigmas que deve sustentar essa área para os próximos séculos, ou seja, o paradigma emergente para a Ciência da Informação, seria o paradigma social, o qual configura uma abordagem sociocultural para essa ciência e as demais profissões que a ela estão relacionadas, tais como as "três Marias", defendidas por Smit (2000), ou seja, a Arquivologia, Biblioteconomia e Museologia.

Para Capurro (2003), a Ciência da Informação, ao espelhar-se no paradigma social, adquire um aspecto mais humanístico e, para tal, deve concentrar seus esforços em prol de um novo objeto, ou seja, seu sustento deve estar na mensagem, por meio de uma abordagem filosófica, tendo como base teórica, a Hermenêutica. Já Araújo (2014) descreve a Ciência da Informação como uma ciência preocupada com as questões sociais e que vem adquirindo contribuição de inúmeras ciências, como a Psicologia e Sociologia, ao abordar a preocupação com o uso e usuários da informação. Por sua vez, Le Coadic (2004) também acredita na contribuição social dessa área, enfatizando a interferência dessa área na produção e uso da informação, os quais viabilizam o consumo com base em necessidades específicas dos usuários dos atuais sistemas e unidades de informação. Sendo assim, entendemos que ao focar na mensagem, na comunicação, no uso e no usuário, o foco das atenções passa a ser as pessoas, uma vez que esses elementos alimentam o processo comunicativo, sendo que esse processo acontece, unicamente, por meio e para os seres humanos.

Assim, este estudo teórico tematiza a Ciência da Informação e sua redefinição na Sociedade Multicultural. Objetiva discorrer acerca das contribuições do paradigma social, refletindo acerca de sua consolidação como paradigma emergente para a Ciência da Informação na Sociedade Multicultural.

No que se refere aos procedimentos metodológicos adotados para alcance do objetivo geral previamente estabelecido, adotou-se pesquisa bibliográfica, considerando a opinião de diversos autores acerca do paradigma social da Ciência da Informação. Para tanto, este estudo recorre à fundamentação teórica acerca da importância do paradigma social, tendo em vista a opinião de alguns pesquisadores inseridos no campo da Ciência da Informação. Assim, são analisadas algumas pesquisas publicadas nos últimos dez anos, no Brasil, com base em pesquisadores dedicados ao campo da Ciência da Informação, como: Saracevic (1996), Capurro (2003), Le Coadic (2004), Mathes (2005), Renault (2007) e Araújo (2014). Além desses, outros autores também são 
referenciados, uma vez que abordam aspectos relacionados ao paradigma social no âmago da Ciência da Informação.

$\mathrm{O}$ artigo está estruturado em três partes, em que são destacados, sequencialmente: os aspectos da Sociedade Multicultural; as características do paradigma social da Ciência da Informação; e, por fim, é apresentada a fundamentação que justifica tal paradigma como emergente para a sociedade pósmoderna.

\section{A SOCIEDADE MULTICULTURAL: LIBERDADE, DIVERSIDADE, DEMOCRATIZAÇÃO E COLABORAÇÃO}

A história das civilizações tem demonstrado o quando o conhecimento é capaz de viabilizar a transformação e o poder. É através do acesso ao conhecimento que as pessoas e as diversas sociedades, ao longo dos tempos, tornaram-se soberanas, estabelecendo formas de dominação, de modo a estabelecer a ordem e controle sobre os que, de alguma forma, não tinham o mesmo nível de conhecimento.

O crescimento de muitas civilizações, no decorrer dos períodos históricos, está ligado à capacidade de adquirir e particularizar o conhecimento, desencadeando uma relação de dominação, em que predominava soberanos e subordinados. Para se firmar esse sistema de desigualdade era preciso instituir um processo de retenção do conhecimento, de modo que ele ficasse restrito aos dominadores, o que proporcionou o processo de monopolização do conhecimento (BURKE, 2003).

Percebe-se que a produção de conhecimento sempre esteve ligada ao processamento da informação, sendo essa materializada em diversas fontes. Nesses períodos de intensa dominação, típicos da Antiguidade, Idade Média e início da Moderna, as unidades de informação já exerciam um importante papel, qual seja, proporcionar acesso à informação acumulada pelas gerações passadas, no intuito de viabilizar a produção de novos conhecimentos para a sociedade do presente e do futuro (MARTINS, 2001).

Não resta dúvida de que, o acesso restrito ao conhecimento proporcionou o engessamento de muitas culturas, assim como estabelecia um sistema previamente formulado, pautado em uma única ou poucas formas de se pensar e interagir em uma sociedade. Trata-se de uma sociedade singular, dotada de costumes e tendências comungadas por uma coletividade e devidamente controladas pelas relações de poder e dominação, relações essas que estavam nas mãos dos que detinham o conhecimento (FOUCAULT, 2009).

Talvez a grande reviravolta dessa sociedade pautada na desigualdade social, nas diferenças de acesso ao conhecimento, devase, em grande parte, à revolução do impresso, de Gutenberg, no século XV. É através de novas formas de se propagar informação, bem como através do barateamento dos recursos informacionais que foi possível assistir no decorrer da Idade Moderna, o processo de democratização do conhecimento (MCGARRY, 1999). Nessa época, arquivos, bibliotecas e museus, segundo Milanesi (2002), passaram a desempenhar uma função social, em que, o desenvolvimento pessoal e profissional de um indivíduo estava ligado à sua capacidade instrutiva, que, por sua vez, era oriundo do processo educacional e por meio do acesso à informação.

Para Milanesi (2002), com a democratização do conhecimento e a partir da criação das bibliotecas públicas, manifesta-se o conceito de cidadania. $O$ acesso à informação e educação é a base para que indivíduos tornem-se instruídos, conhecedores de seus direitos e deveres, por conseguinte, possam questionar o sistema vigente, propondo melhorias e mudança de vida.

Com o avanço das tecnologias e a ampliação no campo das descobertas científicas, a produção de conhecimento é expandida, sobretudo a partir da explosão da informação, a qual contribuiu para intensificar a participação das massas na construção de conhecimento. Na verdade, essa explosão quanto aos registros do conhecimento é intensificada com o surgimento da indústria da informação, no entanto, sua gênese está relacionada com as primeiras técnicas de impressão, através da prensa móvel de Gutenberg (SOLA PRICE, 1993).

$\mathrm{O}$ amplo acesso ao conhecimento e a corrida por informação, viabilizados de modo especial, após a Segunda Guerra Mundial, são 
acontecimentos que serviram para proporcionar uma nova alavancada na sociedade, em que indivíduos buscam por melhores condições de vida, lutam por seus direitos, cobram dos órgãos governamentais, passam a participar do processo político, econômico e social de suas sociedades. Esses fatos, de certa forma, são considerados como emancipatórios, uma vez que despertam nos cidadãos suas capacidades em interferir no meio em que vivem (TOFFLER, 2003).

Nesse contexto, assistiu-se no final do século XX, o crescimento populacional, novas formas de acesso à educação e informação, por conseguinte, o pensamento de liberdade é instituído. A partir daí, surgem grupos dos mais diferenciados, concepções são rompidas, modelos e métodos até então considerados como únicos padrões para proporcionar uma vida decente são refutados. Surge, portanto, uma sociedade com uma "nova cara", em que predominam a liberdade, a diversidade, a democratização e a colaboração (BURKE, 2012).

A Sociedade atual está marcada, quanto aos avanços do conhecimento, no potencial determinado pela informação e pelas novas tecnologias (MCGARRY, 1999). No que se refere às concepções do ser humano, segundo Canen e Canen (2005), tal momento histórico pode ser considerado como Sociedade Multicultural, uma vez que se presa pela diferenciação, pela diversidade, pela liberdade de escolha e pela aceitação do próprio ser humano.

Segundo os autores supracitados,

[...] as perspectivas multiculturais, grosso modo, podem ser delineadas desde visões mais liberais ou folclóricas, que tratam da valorização da pluralidade cultural a partir do conhecimento dos costumes e processos de significação cultural das identidades plurais, até visões mais críticas, cujo foco é, justamente, o questionamento a racismos, sexismos e preconceitos de forma geral, buscando perspectivas transformadoras nos espaços culturais, sociais e organizacionais (CANEN; CANEN, 2005, p. 42, grifo nosso).

Assim, a busca por perspectivas transformadoras requer, a priori, a aceitação do próprio ser humano como um elemento adaptativo e livre em suas escolhas, rompendo com qualquer sistema taxativo e engessado, típico dos modelos préestabelecidos nas sociedades antigas. Essa liberdade do ser humano quanto a sua aceitação nos mais diferenciados modos de vivência foi defendida por Foucault (2009), por meio de algumas de suas teorias, quais sejam: a estética da existência e o cuidado de si, as quais são mantidas por meio da subjetivação não mediada por aparatos disciplinadores. Segundo Foucault:

Pode se caracterizar brevemente essa "cultura de si" pelo fato de que a arte da existência - a techne tou biou sob as suas diferentes formas - nela se encontra dominada pelo princípio segundo o qual é preciso "ter cuidados consigo"; é esse princípio do cuidado de si que fundamenta a sua necessidade, comanda o seu desenvolvimento e organiza a sua prática (FOUCAULT, 2009, p. 49).

Portanto, ao discorrer acerca da Sociedade Multicultural, é preciso perceber que ela está enraizada nos princípios de liberdade, o que viabiliza a libertação do ser humano dos institutos disciplinadores. Isso porque, o sujeito é reflexo do meio em que vive, podendo se constituir, segundo Foucault (2004, p. 291), “[...] através das práticas de sujeição ou, de maneira mais autônoma, através das práticas de liberação, de liberdade [...] a partir, obviamente, de um certo número de regras, de estilo, de convenções que podemos encontrar no meio cultural".

A sociedade com essas características não deveria ser considerada como uma ameaça, mas como oportunização em buscar novas possibilidades de diálogo e interação entre as diversas culturas, tendo em vista garantir o equilíbrio por parte dos direitos de cada cidadão, conferindo-lhes oportunidades de crescimento sem se desprenderem de suas heranças culturais (MIRANDA, 2012).

Para esse teórico, para que essa sociedade se consolide como um modelo mais apropriado ao bem-estar humano - que se defina como o paradigma emergente descrito por Santos (2011) - faz-se necessário criar formas de colaboração entre diferentes culturas, como também a disseminação de informações úteis que desenvolvam o senso crítico e refletivo das pessoas, de modo que haja uma abertura para a concretização de 
direitos e deveres de cada um, de respeito mútuo e de colaboração em busca de benefícios recíprocos entre diferentes grupos e culturas.

Não resta dúvida de que, essa conscientização do ser humano é viabilizada por meio do acesso à educação e à informação, recursos básicos para garantir crescimento pessoal e social, além de viabilizar o exercício da cidadania (MILANESI, 2002). Aqui, presumimos que, a democratização do acesso às informações, de forma universal, por garantir essa conscientização nos indivíduos, certamente, representa uma estratégia para assegurar a paz mundial, como previa o pai da Documentação ${ }^{1}$, quando idealizou, no século XIX, a criação de uma biblioteca unificada, para garantir acesso universal ao conhecimento.

A partir do desenvolvimento tecnológico, o acesso universal é concretizado, o que desencadeia a libertação dos sujeitos, bem como a luta por seus direitos e deveres. Nesse enfoque, a busca por uma Sociedade de multiculturas somente ocorrerá por meio da redefinição de novos paradigmas, em que pese a humanização, uma vez que os paradigmas propostos pela Sociedade Moderna estão revestidos de um aspecto materialista/concreto, desconsiderando as complexidades inerentes ao ser humano (SANTOS, 2011).

Assim, é pertinente refletir acerca dos paradigmas que sustentam a Ciência da Informação, sobretudo por ela ser uma ciência eminentemente abrangente e complexa e por sua imprescindível importância para a consolidação do paradigma emergente para a atual sociedade.

\footnotetext{
${ }^{1}$ Refere-se a Paul Otlet, um dos maiores gênios no âmbito das ciências documentais. Foi um cientista social belga, o qual desenvolveu novas propostas e formas de organização do conhecimento registrado, através de um repertório universal de bibliografias. É considerado como o pai da Documentação, tendo grande contribuição para o desenvolvimento da Ciência da Informação e da Biblioteconomia (SEGUNDO, 2011). Foi o criador, juntamente com La Fontaine, do Sistema de Classificação Universal de documentos, muito utilizado em bibliotecas do mundo inteiro (SOUZA, 2004).
}

\section{O PARADIGMA SOCIAL DA CIÊNCIA DA INFORMAÇÃO: DIÁLOGO COM ALGUNS TEÓRICOS}

A Ciência da Informação, embora possua como uma de suas principais características a interdisciplinaridade com inúmeras outras áreas do conhecimento - como nos ensina Le Coadic (2004), ao propor a metáfora da flor, em que a base seria as ciências documentais, tais como a Arquivologia, Biblioteconomia, Jornalismo e Museologia - possui características que lhe é peculiar, estando sustentada em diversos paradigmas, muitos deles diferentes dos paradigmas inerentes a outras áreas.

Primeiramente, Le Coadic (2004) demonstra a necessidade de redefinição constante desses paradigmas, em virtude da dinamicidade atribuída ao objeto de estudo da Ciência da Informação, que é a informação. Portanto, ao propor o estudo de todo o fluxo da informação, grosso modo, detectam-se três revoluções que afetam os três tempos desse ciclo: o tempo da produção da informação, da comunicação e do uso da informação. Por conseguinte, três paradigmas estão inseridos no contexto dessa ciência, quais sejam: paradigma do trabalho coletivo, o do fluxo e o do usuário. Com o desenvolvimento tecnológico, esses três paradigmas somente acontecem a partir do estabelecimento de um novo paradigma, que é o paradigma tecnológico, descrito pelo autor, como paradigma do elétron.

Esses paradigmas, segundo o referido autor, possuem forte relação com o ser humano, portanto, permite que a Ciência da Informação consolide-se como uma área social. Assim:

A Ciência da Informação, preocupada em esclarecer um problema social concreto, o da informação, e voltada para o ser social que procura a informação, situa-se no campo das ciências sociais (das ciências e do homem e da sociedade), que são o meio principal de acesso a uma compreensão do social e do cultural (LE COADIC, 2004, p. 19, grifo nosso).

O autor ainda defende que essa área do conhecimento humano transferiu-se, de prática de organização de documentos característica essa oriunda das ciências 
documentais, sobretudo da Biblioteconomia para uma ciência social rigorosa, considerando as demandas sociais emergentes e os novos desafios sociais, como também os grandes avanços da Tecnologia da Informação. Ademais, os estudos científicos realizados no início por pesquisadores de fora da área e da profissão, como os de Psicologia, Sociologia, Economia, Informática e Telecomunicações, contribuíram, e muito, para o desenvolvimento científico dessa área do saber.

Para Araújo (2014, p. 122, grifo nosso), a Ciência da Informação

[...] não nasceu como uma ciência tipicamente social, mas identificou-se ao longo dos anos com o escopo das ciências sociais à medida que se orientou para uma postura em que os sujeitos passaram a ser vistos como o principal ator e objetivos dos chamados sistemas de informação, e que métodos e conceitos das ciências humanas e sociais foram aplicados para o seu estudo.

Em linhas gerais, na visão de Araújo (2014, p. 111), a priori, a Ciência da Informação não tem preocupação com a custódia ou posse dos documentos, mas com "[...] a sua circulação e sua disseminação da maneira mais produtiva possível. Depois, o foco não propriamente nos documentos (registro físico), mas em seu conteúdo objetivo ou, dito de outro modo, na informação contida nos documentos".

Portanto, estão relacionados os paradigmas do uso e do usuário, uma vez que o uso requer a presença de um usuário, assim como defende Silva (2006) e Araújo (2014), de que o crescimento dos estudos de uso da informação é suficiente para demonstrar as novas concepções que estão embasando as ciências da informação nesse iniciar de milênio.

$\mathrm{O}$ aspecto interdisciplinar atribuído à Ciência da Informação permite constatar que ela tem como base de sustentação buscar o relacionamento mútuo e integrado entre as diversas teorias e princípios elucidados por outras áreas do conhecimento. Esse fato atesta que essa área pode contribuir com a ampliação de conhecimento, rompendo barreiras até então existentes e estabelecendo novos olhares nas concepções que norteiam os fazeres humanos. Portanto, seu aspecto interdisciplinar permite

[...] fazer dialogar, dentro dela, as contribuições das diferentes áreas do conhecimento. Assim, direcionados pela especificidade do olhar informacional promovido pela Ciência da Informação, conceitos oriundos de áreas díspares como Psicologia, Linguística, Computação, Sociologia e outros são ressignificados na Ciência da Informação, num processo de apropriação que é, ele próprio, a dinâmica interdisciplinar da área (ARAÚJO, 2014, p. 119).

Verifica-se a interação entre diversos paradigmas, que, segundo Capurro (2003), as diversas características, tendências e paradigmas pertencentes à Ciência da Informação, podem ser divididos em três grandes grupos, considerados pelo autor, os três grandes paradigmas que alicerçam a sociedade moderna, que são: paradigma físico, cognitivo e social, os quais viabilizam diversas abordagens para fomentar os estudos acerca dessa ciência como área do conhecimento, que são: abordagem tradicional, alternativa e sociocultural, o que demonstra, por meio dessas distintas abordagens, o aspecto interdisciplinar dessa ciência (CAPURRO, 2003).

Para o referido teórico, o paradigma físico, o qual viabiliza a abordagem tradicional, é aquele em que a informação é estudada como um objeto tangível, o que evidencia a importância aferida ao suporte documental, manifestando-se, nesse paradigma, as técnicas, instrumentos e metodologias de tratamento, processamento e organização de documentos em acervos documentais.

O paradigma cognitivo corresponde a abordagem alternativa, em que a informação é considerada como um insumo dinâmico, em constante movimento, ou seja, a informação é caracterizada não como coisa, mas como processo, o que demonstra sua utilização para diferentes finalidades. Nesse aspecto, considera-se a informação como um constructo que viabiliza a produção de conhecimento, configurando-se diferentes fluxos e canais de informação (CAPURRO, 2003).

Por sua vez, o paradigma social, pautado na abordagem sociocultural, corresponde à 
informação como produtora de conhecimento, sendo que esse conhecimento não pode ser medido, uma vez que está armazenado nas pessoas, constituindo o que se denomina de conhecimento tácito, fruto de experiências, vivências e habilidades pessoais. Nessa concepção, considera-se a preocupação com questões cognitivas, abordando-se estudos e práticas profissionais no contexto do acesso à informação e o comportamento do usuário quanto ao uso dessa informação (CAPURRO, 2003).

É possível constatar o aspecto social da Ciência da Informação, não apenas nas últimas décadas com o aumento das pesquisas sobre comportamento informacional, bem como estudos sobre usabilidade, mas, mesmo que implicitamente, esse paradigma apresenta-se desde a gênese dessa área. Notase isso, quando aparece pela primeira vez na literatura os temos: "uso", "fluxo" e "comportamento informacional", conforme descrito na obra de Borko (1968).

Para esse autor, Ciência da Informação é uma disciplina que investiga as propriedades e o comportamento informacional, as forças que governam os fluxos de informação e os significados do processamento da informação, para uma acessibilidade e usabilidade ótima. Trata-se, na verdade, de uma ciência, a qual possui como principal preocupação o conhecimento acerca da origem, coleção, organização, armazenamento, recuperação, interpretação, transmissão, transformação e utilização da informação.

Nesse conceito clássico trazido por Borko (1968), no momento da criação da Ciência da Informação, no decorrer da década de 1960, já se evidencia uma aproximação dessa ciência com os problemas sociais. Portanto, no atual contexto, segundo Araújo (2014), emergem concepções e práticas profissionais, cujo comprometimento está, primordialmente, relacionado ao resgate do papel de sujeitos ativos e no estudo de suas apropriações, suas diferentes necessidades e usos.

\section{A DEFINIÇÃO DE UM PARADIGMA EMERGENTE PARA A CIÊNCIA DA INFORMAÇÃO}

Com base na preocupação e valorização atribuída aos sujeitos da informação, conforme discorrido na obra de Araújo
(2014), não resta dúvida de que, ao considerar o sujeito como agente ativo na redefinição de serviços e produtos em informação, deve-se considerar a complexidade existente no ser humano, o que requer um paradigma que aceite a diversidade, que entenda a flexibilidade e viabiliza a colaboração mútua, haja vista fomentar uma sociedade multicultural em prol do bem comum, de acordo com Miranda (2012).

Primeiramente, é preciso considerar que o paradigma voltado para o usuário e suas necessidades está contido no paradigma social, uma vez que os usuários constituem os principais elementos da sociedade, pois são eles que vitalizam as práticas sociais e culturais. Portanto, segundo Le Coadic (2004), todos os demais elementos sociais que, juntamente com os usuários, constituem o meio social, devem estar adequados a esses indivíduos. Portanto, é preciso considerar, no que tange às unidades de informação, que,

[...] com o advento das tecnologias eletrônicas (análogas ou digitais) e fotônicas da informação (microcomputadores, quiosques interativos, discos laser, fibras óticas, dispositivos multimídias, videodiscos, informática de gestão de acervos et.), as bibliotecas, centros de documentação, museus e instituições culturais, em geral, não podem mais ser apenas depósitos de livros, documentos, objetos e artefatos (LE COADIC, 2004, p. 17-18).

Entende-se, na fala de Le Coadic (2004), que, na atualidade, houve um desprendimento da Ciência da Informação e áreas corretadas, quanto ao seu objeto de estudo, ou seja, a principal preocupação não está no objeto concreto, mas sim na informação, sendo que essa ainda traz em seu bojo um aspecto "materializado", tendo esse aspecto rompido quando o objeto de estudo passa a ser a mensagem, por conseguinte, a importância conferida ao usuário desses registros e dessa informação, tese também defendida por Capurro (2003).

Para Capurro (2003), citado por Matheus (2005), a preocupação com o social permitiu que a Ciência da Informação contemplasse um objeto de estudo "desmaterializado", ou seja, um objeto em que sua manifestação estava ligada, tão somente, ao ser humano. Portanto, defende uma fundamentação 
filosófica para a área da Ciência da Informação ${ }^{2}$, pautada, principalmente em uma teoria da mensagem, denominada de angelética.

Essa teoria, a priori, foi criada para desambiguizar as complexidades imbuídas no termo "informação", e garantir a valorização do ser humano, pois as mensagens são criações desses sujeitos. Ao mencionar a mensagem como objeto de estudo, considerase todo o processo comunicativo, sendo que é através desse processo que as pessoas adotam mecanismos de liberação, garantindo, dessa forma, a transformação e aceitação do indivíduo, manifestando-se contextos plurais (MATHEUS, 2005; RENAULT, 2007).

Em tese, segundo Matheus (2005), Capurro, ao trabalhar o paradigma social da Ciência da Informação, utiliza a teoria da mensagem, cuja intenção não é criar ou escolher uma definição assertiva de informação, mas buscar discutir aspectos que devem ser considerados pelos estudos dessa área, qual seja: a informação e seu impacto social.

Matheus (2005) e Renaut (2007) consideram a obra de Capurro, sobretudo ao trabalhar o paradigma social, como uma estratégia para demonstrar o aspecto social dessa área, tendo os sujeitos da informação e suas peculiaridades, especial atenção. $\mathrm{O}$ estudo da mensagem, certamente, está mais apropriado para conhecer as necessidades dos usuários, de modo a viabilizar a libertação das pessoas. Ao contrário, a informação não é tão adequada, pois, segundo Matheus (2005, p. 147, grifo nosso), esse recurso "[...] é aquilo que é informativo para uma pessoa, o que é condicionado pela comunidade a qual a pessoa pertence [...]". Dessa forma,

2 Importante reforçar que neste texto não se pretende aprofundar na fundamentação filosófica proposta por Capurro para a Ciência da Informação, conforme fez Matheus (2005) e Renault (2007). De modo geral, esses autores discorreram acerca da importância da hermenêutica, o trilema de Capurro, assim como os aspectos inerentes à angelética. De qualquer forma, essas concepções teóricas trazem, grosso modo, em seu bojo, a necessidade de constante reformulação nas práticas profissionais, as quais devem se colocar a serviço da tríade: tecnologia, usuário e sociedade, conforme defendido nos estudos desses autores. consideramos que o paradigma social, por meio da teoria da mensagem, provoca a liberação individual, refutando interferências e manipulações oriundas de aparatos disciplinadores, conforme descrito por Foucault (2004), como também evidenciado nos argumentos de Santos (2011), acerca da delimitação de um paradigma emergente pautado na humanização.

Ao pensarmos em um paradigma que dê conta das limitações, peculiaridades e escolhas do ser humano, é preciso entender os comportamentos humanos e a possibilidade de mudança desses sujeitos. Assim:

Nas últimas quatro décadas a Ciência da Informação apresentou contribuições que influenciaram o modo como a informação é manipulada na sociedade e pela tecnologia e também permitiu melhor compreensão para um rol de problemas, processos e estruturas associados ao conhecimento, à informação e ao comportamento humano frente à informação (SARACEVIC, 1996, p. 60, grifo nosso).

Para o referido teórico, não se pode deixar de acreditar que a Ciência da Informação é um campo dedicado às questões científicas e à prática profissional voltadas "[...] para os problemas da efetiva comunicação do conhecimento e de seus registros entre os seres humanos, no contexto social, institucional ou individual do uso e das necessidades de informação [...]" (SARACEVIC, 1996, p. 47, grifo nosso). Portando, não resta dúvida de que o paradigma emergente a ser considerado pela Ciência da Informação, nesses novos tempos, deve alicerçar-se nesses conceitos: comunicação, seres humanos, contexto social, institucional e individual, e, por fim, as necessidades dos humanos.

Com efeito, ao abordarmos um paradigma emergente para a sociedade atual, considerando seu aspecto multicultural, percebemos a importância que o ser humano possui nesse processo, aliado à capacidade libertadora e aos ideais de liberdade e igualdade presentes na pós-modernidade. A esse respeito, dialogamos com Lankes (2012), ao vislumbrar novas propostas para as áreas da informação, sobretudo, à Biblioteconomia. Acredita o referido autor que o foco, nesses novos tempos, não deve estar somente nos 
fazeres técnicos, mas principalmente, nas pessoas, pois elas representam a razão de ser dos serviços informacionais e, ao considerar as pessoas, certamente, adentramos em uma sociedade da cultura múltipla, da aceitação e da colaboração.

\section{CONSIDERAÇÕES FINAIS}

Por meio do estudo bibliográfico realizado nesta pesquisa, foi possível discorrer acerca das principais características da Ciência da Informação e sua redefinição na Sociedade Multicultural, considerando a existência de um novo paradigma como método para minimizar os problemas da sociedade pósmoderna.

Constatou-se, após as reflexões apresentadas por inúmeros autores da área, que o paradigma emergente mais adequado à Sociedade Multicultural, diz respeito ao paradigma social, o qual se volta para as necessidades dos sujeitos da informação, e, considerando as limitações e peculiaridades de cada um, manifesta-se a liberdade do ser humano, bem como sua aceitação no contexto social, refutando, dessa forma, aparatos disciplinadores quanto às escolhas, tendências e manifestações culturais no ambiente social. Assim, considerar o ser humano e suas especificidades deve ser um dos principais objetivos da Ciência da Informação, a qual se adentra à humanização a fim de se adequar no mundo pós-moderno.

As propostas do paradigma social de Capurro (2003) em consonância com outros teóricos da área, como em Saracevic (1996), Le Coadic (2004), Araújo (2014), dentre outros, representam uma estratégia viável para garantir a liberdade de direito, assim como, considerar as necessidades dos indivíduos, logo viabiliza a formação de uma sociedade pautada na humanização, o que, certamente, acarretará bem-estar social, satisfação e harmonização. Assim, por meio das concepções oriundas do paradigma social, constata-se que o acesso à informação, a democratização do conhecimento, bem como o estudo da comunicação entre humanos constituem os pilares centrais na promoção de uma sociedade pautada em diferenças, mas conduzida pela libertação e aceitação.

Recebido em: 20/01/2017

Aceito em definitivo em: 27/04/2017

\title{
THE INFORMATION SCIENCE IN THE MULTICULTURAL SOCIETY: THE SOCIAL PARADIGM AS AN EMERGING PARADIGM
}

\begin{abstract}
The paradigms that sustain the areas of knowledge and the related professions must be constantly redefining, considering the new challenges and changes that occur over time. These paradigms must emerge in harmony with the needs of the social environment, considering, mainly, limitations and specificities of the human being. Thus, this theoretical study thematizes Information Science and its redefinition in the Multicultural Society. It aims to discuss the contributions of the social paradigm, reflecting on its consolidation as an emerging paradigm for Information Science in the Multicultural Society. It discusses aspects of the Multicultural Society and the characteristics of the social paradigm of Information Science. It presents a rationale that justifies such a paradigm as emerging for postmodern society and for Information Science. It concludes that access to information, the democratization of knowledge, as well as the study of communication between humans, tendencies derived from the social paradigm, are the central pillars in the promotion of a society based on differences, but driven by liberation and acceptance.
\end{abstract}

Keywords: Multicultural Society. Paradigms of Information Science. Social paradigm. 


\section{REFERÊNCIAS}

ARAÚJO, Carlos Alberto Ávila. Arquivologia, Biblioteconomia, Museologia e Ciência da Informação: o diálogo possível. Brasília: Briquet de Lemos, 2014.

BORKO, H. Information Science: what is it? American Documentation, v. 19, n. 1, p. 35, jan. 1968.

BURKE, Peter. Uma história social do conhecimento: de Gutenberg a Diderot. Rio de Janeiro: J. Zahar, 2003.

\section{Uma história social do}

conhecimento II: da enciclopédia à wikipédia. Rio de Janeiro: Zahar, 2012.

CANEN, Ana; CANEN, Alberto. Rompendo fronteiras curriculares: o multiculturalismo na educação e outros campos do saber.

Currículo sem Fronteiras, v. 5, n. 2, p. 4049, jul./dez. 2005. Disponível em:

$<$ http://www.curriculosemfronteiras.org/vol5i ss2articles/canen.htm>. Acessível em: 24 abr. 2012.

CAPURRO, Rafael. Epistemologia e ciência da informação. In: ENCONTRO NACIONAL DE PESQUISA EM CIÊNCIA DA INFORMAÇÃO, 5., 2003, Belo Horizonte. Anais... Belo Horizonte: Associação Nacional de Pesquisa e Pós-Graduação em Ciência da Informação e Biblioteconomia, 2003.

CUNHA, Miriam Vieira da. As profissões e suas transformações na sociedade. In: ; SOUZA, Francisco das Chagas (Org.). Comunicação, gestão e profissões: abordagens para o estudo da Ciência da Informação. Belo Horizonte: Autêntica, 2006, p. 141-150.

\section{FOUCAULT, Michael. História da}

Sexualidade 2: o uso dos prazeres. Rio de Janeiro: Graal, 2009.

A hermenêutica do sujeito. São Paulo: Martins Fontes, 2004.
LANKES, David. Expect More: Demanding Better Libraries For Today's Complex World. [S.L.]: [sinenomine], 2012.

LE COADIC, Yves-François. A ciência da informação. 2. Ed. Brasília: Briquet de Lemos, 2004.

MARTINS, Wilson. A palavra escrita: história do livro, da imprensa e da biblioteca. 3. ed. São Paulo: Ática, 2001.

MATHES, Renato Fabiano. Rafael Capurro e a filosofia da informação: abordagens, conceitos e metodologias de pesquisa para a Ciência da Informação. Perspectiva em Ciência da Informação, Belo Horizonte, v. 1, n. 2, p. 140-165, jun./dez. 2005.

MCGARRY, Kevin. O Contexto dinâmico da informação: uma análise introdutória. Brasília: Briquet de Lemos, 1999.

MILANESI, Luís. Biblioteca. Cotia: Ateliê Editorial, 2002.

MIRANDA, Tiago Alves. A busca de proteção e fortalecimento de uma Sociedade Multicultural através do diálogo intercultural. 2012. 110 f. Dissertação (Mestrado em Direito) - Programa de pósGraduação em Direito, Faculdade de Direito do Sul de Minas. Belo Horizonte, 2012. Disponível em: < http://www.fdsm.edu.br/site/posgraduacao/dis sertacoes/06.pdf >. Acesso em: 16 maio 2016.

RENAULT, Leonardo Vasconcelos. O retrato da Ciência da Informação: uma análise de seus fundamentos sociais. Encontros Bibli, Florianópolis, n. 23, p. 134-150, 2007.

SANTOS, Boaventura de Sousa. A crítica da razão indolente: contra o desperdício da experiência. São Paulo: Cortez, 2011.

SARACEVIC, Tefko. Ciência da informação: origem, evolução e relações. Perspectiva em Ciência da Informação, Belo Horizonte, v. 1, n. 1, p. 41-62, jan./jun. 1996. Disponível 
em:

$<$ http://portaldeperiodicos.eci.ufmg.br/index.p hp/pci/article/view/235 >. Acesso em: 17 mar. 2016.

SEGUNDO, José Eduardo Santarém. A documentação: Paul Otlet e o facebook. In: CRIPPA, Giulia; MOSTAFA, Solange Puntel (Org.). Ciência da Informação e

Documentação. Campinas: Alínea, 2011, p. 99-112.

SILVA, Armando Malheiro da; RIBEIRO, Fernanda. Das ciências documentais à Ciência da Informação. 2. ed. Porto: Afrontamentos, 2008.

SILVA, Armando Malheiro da. A informação: da compreensão do fenómeno e construção do objecto científico. Porto: Afrontamentos, 2006.

SIQUEIRA, Jéssica Câmara.

Biblioteconomia, documentação e ciência da informação: história, sociedade, tecnologia e pós-modernidade. Perspectivas em Ciência da Informação, v.15, n. 3, p. 52-66, set./dez. 2010. Disponível em:

<http://www.scielo.br/pdf/pci/v15n3/04.pdf>. Acesso em: 16 maio 2016.

SMIT, Johanna. O profissional da informação e sua relação com as áreas de Biblioteconomia/Documentação,

Arquivologia e Museologia. In: VALENTIM, Marta Lígia (Org.). Profissionais da informação: formação, perfil e atuação profissional. São Paulo: Polis, 2000, p. 119134.

SOLLA PRICE, Derek John. Little science, big science. New York: Columbia University Press, 1993.

SOUZA, Sebastião de. CDU: como entender e utilizar a edição-padrão internacional em língua portuguesa. 3. ed. Brasília, DF:

Thesaurus, 2004.

TOFFLER, Alvin. A terceira onda. 27. ed. Rio de Janeiro: Record, 2003.

\footnotetext{
' Os resultados parciais deste estudo foram apresentados no XI Encontro de Diretores e X Encontro de Docentes das Escolas de Biblioteconomia e Ciência da Informação do MERCOSUL (EBCIM, 2016), evento ocorrido em 2016, na cidade de Belo Horizonte.
} 